\title{
Evaluation of Bayesian models for analysis of crude protein requirement for pigs of
}

\section{Brazilian Piau breed}

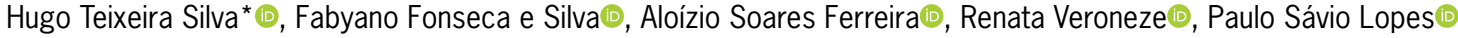

Universidade Federal de Viçosa - Depto. de Zootecnia, Av. Peter Henry Rolfs, s/n - 36570-000 - Viçosa, MG - Brasil. *Corresponding author <hugots.silva@gmail.com>

Edited by: Gerson Barreto Mourão

Received July 18, 2017

Accepted February 08, 2018

\begin{abstract}
We evaluated the inclusion of information on genetic relationship into the analysis of crude protein requirement in diets for pigs of Brazilian Piau breed, using Bayesian inference. The animals were assigned to treatments in a completely randomized design in factorial scheme $4 \times 2$ (crude protein levels $\times$ sex) with 12 repetitions per treatment. The evaluations were carried out in the initial, growing and finishing phases, and after slaughter. The traits evaluated were feed conversion (FC), backfat thickness (BF), daily weight gain (DWG), daily feed intake (DFI) and some carcass cuts. Three models were considered to evaluate the inclusion of information on genetic relationship into the analysis: Model I, a simple linear model; Model II, the same effects of Model I with addition of the independent random effect of animal; and Model III, the same effects of Model II, but including the genetic relationship between the animals. Model III presented the best fit and was considered for later inferences. Crude protein (CP) levels did not significantly influence any of the evaluated traits. The effect of sex was significant only for the growing phase, while its interaction with protein levels presented an opposite result for all evaluated traits. Additionally, CP levels of $10.2 \%, 9.6 \%$ and $9.0 \%$ can be used in diets for pigs of Brazilian Piau breed in the initial, growing and finishing phases, respectively.

Keywords: Bayesian inference, genetic relationship, model selection, performance
\end{abstract}

\section{Introduction}

The statistical model directly influences the reliability of experimental data analysis. Thus, it is essential to find efficient models to describe the variables of interest in function of the factors that affect them.

Most studies on nutritional requirements for pigs have used classical statistical approaches based on fixed effect models. However, in some situations, sources of random variation must be considered, which are usually analyzed using a mixed model framework. Both Bayesian and classical approaches address well the mixed model theory; however, the Bayesian inference presents some advantages in terms of covariance modeling for random effects, model comparison, and direct access of interval estimation and incorporation of prior unknown parameters (Blasco, 2017). Although Bayesian methods have been applied in different scientific fields, only recently these approaches could be used in animal nutrition studies (Moraes et al., 2014; Old et al., 2015; Rossi et al., 2016). Moreover, Bayesian models have been developed to address complex situations in livestock, such as dynamic nutrition (Reed et al., 2016) and nitrogen prediction experiments (Reed et al., 2014).

Over the years, several studies have been performed to determine the optimal level of crude protein $(\mathrm{CP})$ in diets of commercial pig breeds, resulting in higher yield with lower environmental impact (Ball et al., 2013). However, these studies are scarce for local Brazilian pig breeds, such as the Piau. This breed differs from commercial lines due to the high fat deposition, rusticity and the adaptability to farming systems with a low technological level (Souza Júnior et al., 2014).
Thus, these divergences are expected to result in different nutritional requirements. In addition, studies on animal nutrition usually disregard the individual effect of the animals and possible genetic relationships between them. Therefore, such effects may lead to bias in the results of these studies.

In this context, we aimed to compare different models under a Bayesian approach to evaluate the inclusion of individual animal effect and information on genetic relationship into the nutritional analysis. Additionally, we assessed the nutritional requirement of $\mathrm{CP}$ in diets for barrows and gilts of the Brazilian Piau pig breed during the initial, growing and finishing phases.

\section{Materials and Methods}

The experiment was carried out in Viçosa, Minas Gerais State, Brazil $\left(20^{\circ} 45^{\prime} 14^{\prime \prime} \mathrm{S}, 42^{\circ} 52^{\prime} 55^{\prime \prime} \mathrm{W}\right.$, altitude $648 \mathrm{~m}$ ) and it complies with the Ethics Committee on the Use of Animals of Federal University of Viçosa (CEUA: 6/2011).

\section{Experimental design and measurement}

The experiment was divided into three phases according to the growth stage: initial (15 - $35 \mathrm{~kg})$, growing $(35-65 \mathrm{~kg})$ and finishing $(65-90 \mathrm{~kg})$ phases. In all phases, we measured the variables feed conversion $(\mathrm{FC})$, backfat thickness (BF), daily weight gain (DWG) and daily feed intake (DFI). The animals were assigned to the treatments according to a completely randomized design in factorial scheme $4 \times 2$ (four crude protein levels; sex: castrated male and female) with 12 repetitions per treatment. The animals were divided into two 
batches according to their birth dates to be accommodated in the same experimental structure. During the experimental period, the animals were individually housed in pens with concrete floor, semi-automatic feeders and nipple drinkers. Pigs had ad libitum access to feed and water.

The CP levels evaluated were: $10.2 \%, 12.6 \%$, $15.0 \%$ and $17.4 \%$ in the initial phase; $9.6 \%, 12.0 \%$, $14.4 \%$ and $16.8 \%$ in the growing phase and $9.0 \%$ $10.6 \%, 12.2 \%$ and $13.8 \%$ in the finishing phase. The experimental diets were formulated based on the nutritional requirements of pigs according to Rostagno et al. (2011). The variations in the CP levels were obtained by proportional variation of corn and soybean meal supplemented with industrial amino acids. The diets were isoenergetic and the minimum proportion of lysine in different protein levels was kept.

The evaluations in the initial phase were performed during 45 days, with the animals presenting initial weight and age averages equal to $15.0 \pm 2.6 \mathrm{~kg}$ and $75 \pm 7.8$ days, respectively. The evaluations of the other two phases were performed during 35 days. For the growing phase, the initial weight and age averages were equal to $35.0 \pm 4.0 \mathrm{~kg}$ and $127 \pm 10.2$ days, respectively, whereas for the finishing phase, these values were $65.2 \pm 4.2 \mathrm{~kg}$ and $172 \pm 7.7$ days, respectively. After evaluations in the finishing phase, the same diets were offered to the animals until slaughter $197 \pm 2 \mathrm{~kg}$ of live weight), when the warm carcass weight was measured. Posteriorly, the carcasses were sawn lengthwise and stored in a cold chamber at $4{ }^{\circ} \mathrm{C}$ for $24 \mathrm{~h}$. Afterward, the loin eye area, rib, pork chop, backfat thickness and ham weight were measured from the left half carcass. Although repeated-measures models are often used in animal science experiments, in pig nutrition, each phase is evaluated separately. The reason is the great difference in animal husbandry systems, specific for each phase, and mainly due to differences in nutritional requirements that demand distinct diets for each phase (Bedford et al., 2016).

\section{Statistical analysis}

The statistical analyses were performed using Bayesian inference under three different models: Model I) Simple linear model considering as systematic effects the treatments (linear and quadratic), batch, sex, interaction between treatment and sex and initial weight as linear covariate. The quadratic regression outperformed the linear regression considering the same goodnessof-fit measurements described in detail later. Model II) Mixed linear model with the same systematic effects of Model I with addition of the independent animal random effect. Model III) Mixed linear model with the same effects of Model II and considering the genetic relationship between the animals. The genetic relationship matrix was set up using the complete pedigree of Piau pig population of the Federal University of Viçosa, which included 1,398 animals.
The matrix representation of the models is:

Model I: $y=X \beta+\varepsilon ;$

Models II and III: $y=X \beta+Z u+\varepsilon$;

where: $y_{(48 \times 1)}$ is the vector of observations; $\beta_{(7 \times 1)}$ is the vector of systematic effects; $X_{(48 \times 7)}$ is the incidence matrix of $\beta_{;} u_{(48 \times 1)}$ is the vector of the animal random effect; ${ }_{(48 \times 48)}$ is the incidence matrix of $u ; \varepsilon$ is the vector of residual effects. The conditional distribution of $y$ given the parameters was assumed to follow a normal distribution. Thus, $y \mid \beta, \sigma_{\varepsilon}^{2} \sim N\left(X \beta, I \sigma_{\varepsilon}^{2}\right)$ for Model I; and $y \mid \beta, u, \sigma_{\varepsilon}^{2} \sim N\left(X \beta+Z u, I \sigma_{\varepsilon}^{2}\right)$ for Models II and III in which I is the identity matrix. The normal distribution was also assumed for parameter $\beta$, such that $\beta \mid \sigma_{\beta}^{2} \sim N\left(0, I \sigma_{\beta}^{2}\right)$. The value of $1 \times 10^{9}$ was assigned for $\sigma_{\beta}^{2}$, which corresponds to a non-informative prior distribution for parameter $\beta$. A normal distribution was also assumed for the animal random effect, such that $u \mid \sigma_{\alpha}^{2} \sim N\left(0, I \sigma_{\alpha}^{2}\right)$ in Model II and $u \mid \sigma_{\alpha}^{2} \sim N\left(0, A \sigma_{\alpha}^{2}\right)$ in Model III in which $A_{(48 \times 48)}$ is the numerator relationship matrix. Only the animals used in the experiment were considered in $A$ matrix; however, $A$ was obtained as a submatrix from a general relationship matrix set up from the complete pedigree. For the error and animal variances $\left(\sigma_{\varepsilon}^{2}\right.$ and $\left.\sigma_{\alpha}^{2}\right)$, we assumed the scaled inverse chi-square distribution. Thus, $\sigma_{\varepsilon}^{2} \mid v_{\varepsilon}, s_{\varepsilon}^{2} \sim \chi^{-2}\left(v_{\varepsilon}, s_{\varepsilon}^{2}\right)$ and $\sigma_{\alpha}^{2} \mid v_{\alpha}, s_{\alpha}^{2} \sim \chi^{-2}\left(v_{\alpha}, s_{\alpha}^{2}\right)$ in which $v_{\varepsilon}$ and $v_{\alpha}=-2$ and $s_{\alpha}^{2}$ and $S_{\varepsilon}^{2}=1 \times 10^{-6}$ (Sorensen and Gianola, 2002). These values characterized non-informative proper prior distributions, because no previous studies on nutritional requirements for the Brazilian Piau breed were available.

The goodness-of-fits of the models were compared using the Deviance Information Criteria (DIC) developed by Spiegelhalter et al. (2002), which is based on the sum of deviance and the effective number of parameters, such that: $D I C=D(\bar{\theta})+2 p_{D}$ in which $D(\bar{\theta})$ is the likelihood-based deviance estimate of the evaluated model and $p_{D}$ is the effective number of parameters in the model. The smallest DIC value implies the best fit. However, DIC only expresses if one model presented the best fit in relation to other models, but the magnitude of this difference is subjective. To complement this information, the Model Posterior Probabilities (MPP) were calculated, as presented by Wilberg and Bence (2008), which is given by:

$p\left(M_{t} \mid \theta\right)=\exp \left(-\frac{\Delta_{t}}{2}\right) / \sum_{t=1}^{3} \exp \left(-\frac{\Delta_{t}}{2}\right)$,

$t=$ Model I, Model II and Model III in which $p\left(M_{t} \mid \theta\right)$ is the posteriori probability of model $t$ to be the best among the set of models compared, $\Delta_{t}$ is the DIC difference between model $t$ and the model that presented the smallest DIC value. The best model was used to make inferences about the parameters of interest.

Later distributions of the parameters in Models I, II and III were obtained by the Markov Chain Monte 
Carlo (MCMC) method using the package MCMCglmm (Hadfield, 2010) implemented in the R software (R Development Core Team, version 3.4.0). Three hundred thousand samples were generated, assuming a burn-in period and sampling interval of 100,000 and 20 iterations, respectively. Thus, the marginal density estimation was based on 10,000 samples for each parameter. The convergence was evaluated through the Geweke test and the graphical analysis. The significances of the estimated parameters were tested through $95 \%$ credibility intervals (P2.5\%, P97.5 \%) of the posterior means. If the treatment effect expressed significance, contrasts between the CP levels evaluated could be tested (Rossi et al., 2014).

\section{Results and Discussion}

The means of the traits and the respective coefficient of variations are presented in Table 1 . The results show the particular traits of local Brazilian Piau pig breed, which presented low performance and high ability to deposit fat during the experiment. These data agree with Serão et al. (2011), Sousa Júnior et al. (2014) and Veroneze et al. (2014). The coefficients of variation were low to moderate in magnitude (4.93 to 20.31), indicating that the experimental analyses were performed with the necessary precision to ensure interpretation of the results. In general, according to Sakomura et al. (2015), the coefficient of variation of feeder pigs ranged from 0.06 to 0.17 , with an average variation of 0.11 .
The Geweke test and the graphical analyses showed that MCMC chains reached convergence for all parameters of the models evaluated.

\section{Model fitting}

The most appropriate model to evaluate the nutritional requirement of CP for Piau pig breed was identified through DIC and MPP. Model III presented the lowest DIC value followed by Model II and then Model I (Table 2). Moreover, the highest MPP values were observed for Model III, with values close to 1 for all traits evaluated (Table 2).

Considering the DIC values, the best fit of Model II compared with Model I indicates that the variance attributed to the animal effect, which is not considered in Model I, may be inflating the residual variance. This result suggests that the pigs do not present identical responses to the nutrients ingested, despite belonging to the same population (German et al., 2003). Therefore, the random effect of animal should be included in the statistical model for the analysis of experimental data of $\mathrm{CP}$ requirement. In addition, the Piau pig population used in this study is kept for genetic conservation purposes thus the population has not been subjected to any selection process, which contributes to this result.

The lower DIC values of Model III indicate the superiority of this model over the others. Furthermore, the higher MPP values for Model III reinforce this result, indicating that the genetic relationship between animals also represents an important source of variability in the

Table 1 - Means of performance and carcass traits of barrows and gilts (in parenthesis) for different crude protein levels evaluated during three growth phases and after slaughter.

\begin{tabular}{|c|c|c|c|c|c|c|}
\hline \multirow{2}{*}{ Phases } & \multirow{2}{*}{ Traits } & \multicolumn{4}{|c|}{ Treatments (\%) } & \multirow[t]{2}{*}{$\mathrm{CV}(\%)^{*}$} \\
\hline & & 10.20 & 12.60 & 15.00 & 17.40 & \\
\hline \multirow{4}{*}{ 丞 } & $\mathrm{FC}\left(\mathrm{kg} \mathrm{kg}^{-1}\right)$ & $3.34(3.30)$ & $3.29(3.37)$ & $3.10(3.25)$ & $3.55(3.26)$ & 9.15 \\
\hline & $\mathrm{BF}(\mathrm{mm})$ & $12.16(11.50)$ & $13.80(12.00)$ & $11.83(11.16)$ & $11.50(12.16)$ & 18.39 \\
\hline & DWG $\left(\mathrm{kg} \mathrm{d}^{-1}\right)$ & $0.47(0.43)$ & $0.50(0.50)$ & $0.52(0.49)$ & $0.50(0.51)$ & 18.90 \\
\hline & DFI $\left(k \mathrm{~d} \mathrm{~d}^{-1}\right)$ & $1.58(1.40)$ & $1.66(1.72)$ & 1.69 (1.59) & $1.75(1.67)$ & 17.80 \\
\hline \multirow{5}{*}{ 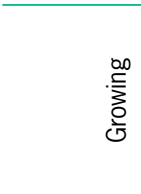 } & & 9.60 & 12.00 & 14.40 & 16.80 & \\
\hline & $\mathrm{FC}\left(\mathrm{kg} \mathrm{kg}^{-1}\right)$ & $4.03(3.80)$ & $3.90(4.06)$ & $3.74(3.83)$ & $4.13(3.69)$ & 8.63 \\
\hline & $\mathrm{BF}(\mathrm{mm})$ & $24.16(25.30)$ & $24.00(24.33)$ & $24.25(22.50)$ & $23.33(22.83)$ & 19.01 \\
\hline & DWG $\left(\mathrm{kg} \mathrm{d}^{-1}\right)$ & $0.57(0.70)$ & $0.53(0.65)$ & $0.60(0.63)$ & $0.58(0.64)$ & 14.58 \\
\hline & DFI $\left(\mathrm{kg} \mathrm{d}^{-1}\right)$ & $2.68(2.32)$ & $2.07(2.14)$ & $2.23(2.41)$ & $2.39(2.37)$ & 12.34 \\
\hline \multirow{5}{*}{ } & & 9.00 & 10.60 & 12.20 & 13.80 & \\
\hline & $\mathrm{FC}\left(\mathrm{kg} \mathrm{kg}^{-1}\right)$ & $4.79(4.30)$ & $4.56(4.60)$ & $4.32(4.55)$ & $4.36(4.65)$ & 13.96 \\
\hline & $\mathrm{BF}(\mathrm{mm})$ & $29.00(27.16)$ & $29.30(29.00)$ & $30.83(32.16)$ & $32.16(27.83)$ & 16.50 \\
\hline & DWG $\left(\mathrm{kg} \mathrm{d}^{-1}\right)$ & $0.56(0.58)$ & $0.62(0.51)$ & $0.63(0.56)$ & $0.63(0.46)$ & 20.31 \\
\hline & DFI $\left(k d^{-1}\right)$ & $2.63(2.49)$ & $2.83(2.39)$ & $2.70(2.48)$ & $2.77(2.15)$ & 16.13 \\
\hline \multirow{7}{*}{ 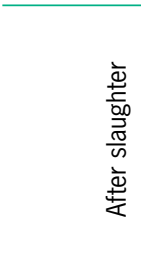 } & & 9.00 & 10.60 & 12.20 & 13.80 & \\
\hline & Warm carcass (kg) & $85.38(83.28)$ & $81.90(79.47)$ & $83.59(78.58)$ & $82.96(79.10)$ & 4.93 \\
\hline & Pork chop (kg) & 7.30 (7.19) & $7.21(7.38)$ & $7.68(6.72)$ & $7.62(6.60)$ & 16.65 \\
\hline & Rib (kg) & 7.89 (6.92) & $7.38(6.83)$ & $7.46(6.97)$ & $7.58(6.78)$ & 13.75 \\
\hline & Ham (kg) & $9.73(9.65)$ & $9.33(8.92)$ & $9.31(8.98)$ & $9.36(9.12)$ & 6.92 \\
\hline & $\mathrm{BF}(\mathrm{mm})$ & $49.33(43.33)$ & $44.66(42.33)$ & $49.50(46.00)$ & $50.77(48.30)$ & 7.70 \\
\hline & Loin eye area $\left(\mathrm{cm}^{2}\right)$ & $28.66(26.16)$ & $27.55(28.2)$ & $26.00(27.33)$ & $23.66(25.30)$ & 16.70 \\
\hline
\end{tabular}

${ }^{*} \mathrm{CV}(\%)=$ coefficient of variation; FC = feed conversion; BF = backfat thickness; DWG = daily weight gain; DFI = daily feed intake. 
Table 2 - Estimates of the Deviance Information Criterion (DIC) and the model posterior probability (MPP) for the fitted models for performance data on three phases and carcass traits after slaughter.

\begin{tabular}{|c|c|c|c|c|c|c|c|}
\hline \multirow{2}{*}{ Phases } & \multirow{2}{*}{ Traits } & \multicolumn{2}{|c|}{ Model I } & \multicolumn{2}{|c|}{ Model II } & \multicolumn{2}{|c|}{ Model III } \\
\hline & & DIC & MPP & DIC & MPP & DIC & MPP \\
\hline \multirow{4}{*}{ 즘 } & FC & 27.44 & $\approx 0$ & 21.53 & $\approx 0$ & -33.12 & $\approx 1$ \\
\hline & $\mathrm{BF}(\mathrm{n}$ & 206.76 & $\approx 0$ & 105.15 & $\approx 0$ & $36.82^{*}$ & $\approx 1$ \\
\hline & & 64.67 & $\approx 0$ & -100.48 & 0.11 & 60 * & 0.89 \\
\hline & & 5.63 & $\approx 0$ & -23.91 & 0.01 & & 0.99 \\
\hline \multirow{4}{*}{ 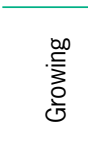 } & $F C(\mathrm{k}$ & 44.3 & $\approx 0$ & 5.22 & $\approx 0$ & $-24.18^{*}$ & $\approx 1$ \\
\hline & . & 269.26 & $\approx 0$ & 130.9 & $\approx 0$ & 36 & $\approx 1$ \\
\hline & DWG & -99.42 & $\approx 0$ & -103.10 & 0.03 & $-109.94^{*}$ & 0.97 \\
\hline & & 5.4 & $\approx 0$ & -24.66 & 0.01 & $-41.68^{*}$ & * 0.99 \\
\hline \multirow{4}{*}{ 竞 } & FC (k & 03.56 & $\approx 0$ & 45.16 & $\approx 0$ & $5.83^{*}$ & $\approx 1$ \\
\hline & 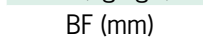 & 309.8 & $\approx 0$ & 165.17 & $\approx 0$ & $40.47^{*}$ & $\approx 1$ \\
\hline & $V G$ & -69.18 & $\approx 0$ & -84.27 & 0.08 & $-89.27^{*}$ & ${ }^{*} 0.92$ \\
\hline & & 35.48 & $\approx 0$ & 10.55 & 0.01 & $-31.71^{*}$ & * 0.99 \\
\hline \multirow{6}{*}{ 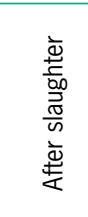 } & Warm car & 218.67 & $\approx 0$ & 121.65 & $\approx 0$ & $48.1^{*}$ & $\approx 1$ \\
\hline & $\pi \mathrm{K}$ & 158.37 & $\approx 0$ & 78.63 & $\approx 0$ & $31.39 *$ & $\approx 1$ \\
\hline & . & 100.00 & $\approx 0$ & 41.88 & $\approx 0$ & $13.43^{*}$ & $\approx 1$ \\
\hline & & 84.31 & $\approx 0$ & 36.1 & $\approx 0$ & $1.46^{*}$ & $\approx 1$ \\
\hline & & 84.59 & $\approx 0$ & 47.18 & $\approx 0$ & $-2.73^{*}$ & $\approx 1$ \\
\hline & Loin eye area $\left(\mathrm{cm}^{2}\right.$ & 295.44 & $\approx 0$ & 152.87 & $\approx 0$ & $73.76^{*}$ & $\approx 1$ \\
\hline
\end{tabular}

*Lower DIC value corresponds to the best fitting model; $F C=$ feed conversion; $\mathrm{BF}=$ backfat thickness; $\mathrm{DWG}=$ daily weight gain; $\mathrm{DFI}=$ daily feed intake.

statistical analysis of experimental data. Therefore, the use of this information is valuable to obtain reliable results in all growing phases evaluated. The experimental designs are set up to control variability sources that could influence the outcomes of the experiment. However, it is impracticable to design an experiment taking into account the differences in the degrees of genetic relationship between animals of a population. In this context, the use of the numerator relationship matrix associated to the animal random effect (Model III) avoids the inclusion of the variation due to relationship with the residual, which implies in results that are more accurate. As Model III showed the best fit, it was used to make inferences about the parameters of interest.

\section{Crude protein requirement}

The posterior means and credibility intervals for parameters from Model III are shown in Table 3. The significance of the effects included into the model was determined using the credibility intervals. If the interval did not include null values, the effect was considered significant. The sex effect $\left(\beta_{4}\right)$ was significant only for DFI in the growing phase. This result is in agreement with Serrano et al. (2009), who studied Iberian pigs and found higher feed intake for barrows than gilts during a similar period of evaluation. According to Xue et al. (1997), gonadotrophic hormones (androgens and estrogens) have different mechanisms to express their anabolic effects on the body of pigs, affecting traits such as feed intake and protein deposition capacity. Thus, the absence of these hormones in barrows may be the cause of differentiated performance compared with gilts.

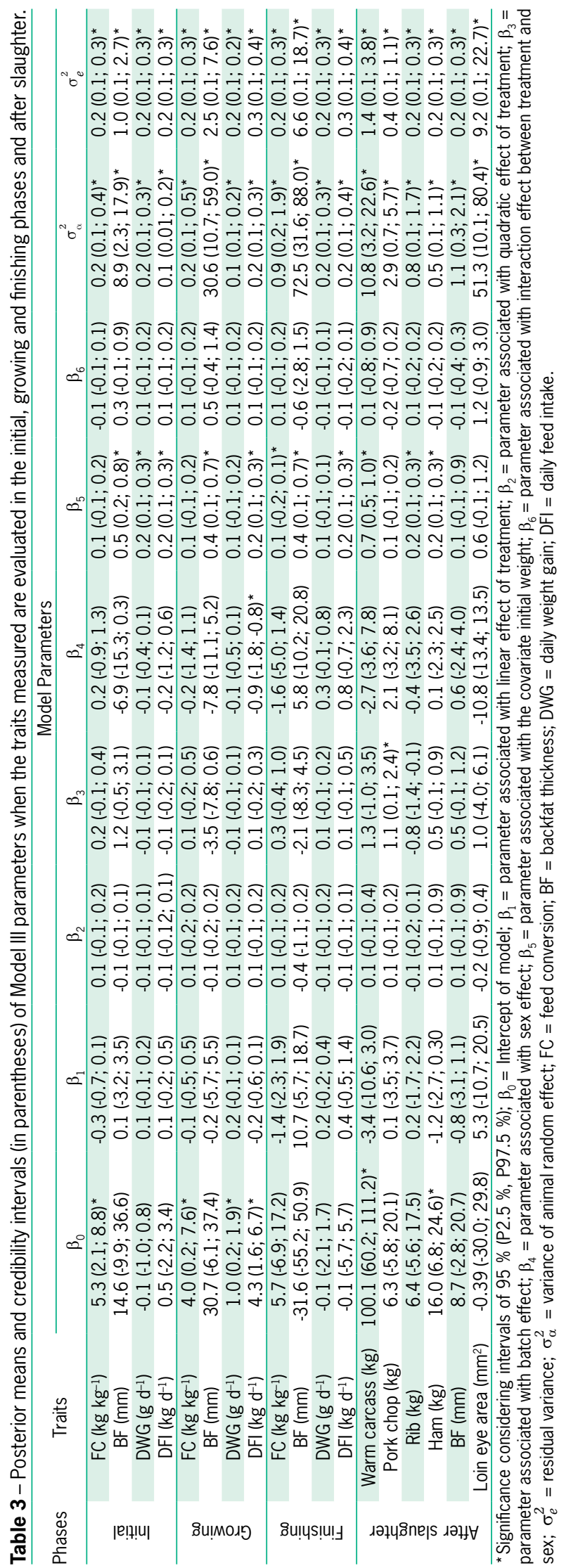


The non-significance of sex effect in the initial phase was also expected, since production of sex hormones in gilts is minimal due to the early age, which allows similar performance for both sexes. The lack of significance of sex effect in the finishing phase was also reported by Serrano et al. (2009), who studied Iberian pigs in a similar period.

We also did not find pronounced effects of sex on carcass cuts, which disagrees with the results from studies performed on Iberian pigs (Latorre et al., 2003; Serrano et al., 2009). This divergence may be attributed to the genetic differences between breeds and different production goals, because even though both breeds stand out for the high fat deposition, Iberian pigs have been used to produce cured products, which also makes the producer focus on some specific cuts.

There was no interaction between treatment and sex $\left(\beta_{6}\right)$ for any phase and traits evaluated, which indicates that $\mathrm{CP}$ levels and sex were independent for the phases and traits evaluated.

Although the quadratic outperformed the linear regression in previous analysis (lower DIC and higher MPP), the CP levels $\left(\beta_{1}\right.$ and $\left.\beta_{2}\right)$ did not significantly influence any of the characteristics in any of evaluated phases, neither for carcass measurements. Thus, a diet with CP levels of $10.2 \%, 9.6 \%$ and $9.0 \%$ can be used for Piau pig breed in the initial, growing and finishing phases, respectively, without compromising the performance and carcass traits. These results demonstrate that $\mathrm{CP}$ requirement of the local Brazilian Piau breed is in fact lower than that recommended for commercial pig breeds (17.35 $\%, 15.80 \%$ and $12.71 \%$, for initial, growing and finishing phases, respectively), as presented by Rostagno et al. (2011). However, the results indicate the need for further studies to evaluate the effect of lower CP levels than those observed in this study for this pig breed.

Although Piau animals show productive indexes lower than the required by the swine industry, the results of this study demonstrate the social importance of this breed, since the lower nutritional requirement makes this breed a suitable alternative to animal husbandry systems with low technological level, which normally are founded in low-income properties. In addition, the characteristics of this breed opens the possibility for its use on organic production and specialized products with high added economic value, such as cured cuts, as it is done with Iberian pigs in Spain.

\section{Conclusion}

The use of animal random effect with the respective genetic relationship information in statistical models for animal experimental analysis is of great relevance, therefore, its inclusion is indicated in future studies. The CP levels of $10.2 \%, 9.6 \%$ and $9.0 \%$ can be used in diets for pigs of local Brazilian Piau breed in the initial, growing and finishing phases, respectively; however, future studies should be carried out to evaluate lower CP levels.

\section{Acknowledgements}

We thank the CNPq (Conselho Nacional de Desenvolvimento Científico e Tecnológico), the CAPES (Coordenação de Aperfeiçoamento de Pessoal de Nível Superior) and FAPEMIG (Fundação de Amparo à Pesquisa do Estado de Minas Gerais) for the financial support, and the Unidade de Ensino, Pesquisa e Extensão em Suinocultura of Universidade Federal de Viçosa for providing the animals and structure necessary to carry out the experiments.

\section{Authors' Contributions}

Conceptualization: Silva, H.T., Ferreira, A.S., Lopes, P.S. Data acquisition: Silva, H.T., Veroneze, R., Lopes, P.S. Data analysis: Silva, H.T.; Silva, F.F. Design of Methodology: Silva, H.T., Silva, F.F., Ferreira, A.S., Lopes, P.S. Writing and editing: Silva, H.T., Silva, F.F., Ferreira, A.S., Veroneze, R., Lopes, P.S.

\section{References}

Ball, M.E.E.; Magowan, E.; McCracken, K.J.; Beattie, V.E.; Bradford, R.; Gordon, F. J.; Robinson, M.J.; Smyth, S.; Henry, W. 2013. The effect of level of crude protein and available lysine on finishing pig performance, nitrogen balance and nutrient digestibility. AsianAustralasian Journal of Animal Sciences 26: 564-572.

Bedford, M.R.; Choct, M.; O'Neill, H.V.M. 2016. Nutrition Experiments in Pigs and Poultry: A Practical Guide. CABI, Wallingford, UK.

German, J.B.; Roberts, M.A.; Watkins, S.M. 2003. Personal metabolomics as a next generation nutritional assessment. The Journal of Nutrition 133: 4260-4266.

Hadfield, J.D. 2010. MCMC methods for multi-response generalized linear mixed models: the MCMCglmm R package. Journal of Statistical Software 33: 1-22.

Latorre, M.A.; Lázaro, R.; Gracia, M.I.; Nieto, M.; Mateos, G.G. 2003. Effect of sex and terminal sire genotype on performance, carcass characteristics, and meat quality of pigs slaughtered at $117 \mathrm{~kg}$ body weight. Meat Science 65: 1369-1377.

Moraes, L.E.; Kebreab, E.; Strathe, A.B.; France, J.; Dijkstra, J.; Casper, D.P.; Fadel, J. G. 2014. Bayesian analysis of energy balance data from growing cattle using parametric and non-parametric modelling. Animal Production Science 54: 2068-2081.

Old, C.A.; Rossow, H.A.; Famula, T.R. 2015. Partitioning of feed intake into maintenance and gain in growing beef cattle: evaluation of conventional and Bayesian analyses. Journal of Animal Science 93: 4826-4842.

Reed, K.F.; Moraes, L.E.; Fadel, J.G.; Casper, D.P.; Dijkstra, J.; France, J.; Kebreab, E. 2014. Prediction of nitrogen use in dairy cattle: a multivariate Bayesian approach. Animal Production Science 54: 1918-1926.

Reed, K.F.; Arhonditsis, G.B.; France, J.; Kebreab, E. 2016. Bayesian calibration of dynamic ruminant nutrition models. Journal of Dairy Science 99: 6362-70

Rossi, R.M.; Martins, E.N.; Lopes, P.S.; Silva, F.F. 2014. Univariate and bivariate Bayesian analysis for feed conversion of the Piau swine breed. Pesquisa Agropecuária Brasileira 49: 754-761 (in Portuguese, with abstract in English). 
Rossi, R.M.; Martins, E.N.; Lopes, P.S.; Silva, F.F.; Marcondes, M.I.; Caetano, G.C.; Ferreira Júnior, H.C.; Knuup, L.S.; Ferreira, M.A. 2016. Bayesian inference of feed conversion in different animal experiments. Arquivo Brasileiro de Medicina Veterinária e Zootecnia 68: 466-474 (in Portuguese, with abstract in English).

Rostagno, H.S.; Albino, L.F.T.; Donzele, J.L.; Gomes, P.C.; Oliveira, R.F.; Lopes, D.C.; Ferreira, A.S.; Barreto, S.L.T.; Euclides, R.F. 2011. Brazilian Tables for Poultry and Swine: Composition of Feedstuffs and Nutritional Requirements $=$ Tabelas Brasileiras para Aves e Suínos: Composição de Alimentos e Exigências Nutricionais. 3ed. Editora UFV, Viçosa, MG, Brazil (in Portuguese).

Sakomura, N.K.; Gous, R.M.; Kyriazakis, I.; Hauschild, L. 2015. Nutritional modelling for pigs and poultry. CABI, Wallingford, UK.

Serão, N.V.L.; Veroneze, R.; Ribeiro, A.M.F.; Verardo, L.L.; Braccini Neto, J.; Gasparino, E.; Guimarães, S.E.F. 2011. Candidate gene expression and intramuscular fat content in pigs. Journal of Animal Breeding and Genetics 128: 28-34.

Serrano, M.P.; Valencia, D.G.; Fuentetaja, A.; Lázaro, R.; Mateos, G.G. 2009. Influence of feed restriction and sex on growth performance and carcass and meat quality of Iberian pigs reared indoors. Journal of Animal Science 87: 1676-1685.
Sorensen, D.; Gianola, D. 2002. Likelihood, Bayesian and MCMC Methods in Quantitative Genetics. Statistics for Biology and Health. Springer, New York, NY, USA.

Souza Júnior, A.A.O.; Lopes, P.S.; Costa, E.V.; Silva, H.T. 2014. The Piau breed in Brazil = A raça Piau no Brasil. p. 315-355. In: Silva Filha, O.L., ed. The Ibero-American swine breeds: an ethno zootechnical approach $=$ As raças suínas Iberoamericanas: um enfoque etnozzotécnico. Instituto Federal de Educação, Ciência e Tecnologia, Salvador, BA, Brazil (in Portuguese).

Spiegelhalter, D.J.; Best, N.G.; Carlin, B.P.; Van Der Linde, A. 2002. Bayesian measures of model complexity and fit. Journal of the Royal Statistical Society 64: 583-639.

Veroneze, R.; Lopes, P.S.; Guimarães, S.E.F.; Guimarães, J.D.; Costa, E.V.; Faria, V.R.; Costa, K.A. 2014. Using pedigree analysis to monitor the local Piau pig breed conservation program. Archivos de Zootecnia 63: 45-54.

Wilberg, M.J.; Bence, J.R. 2008. Performance of deviance information criterion model selection in statistical catch-at-age analysis. Fisheries Research 93: 212-221.

Xue, J.; Dial, G.D.; Pettigrew, J.E. 1997. Performance, carcass, and meat quality advantages of boars over barrows. Journal of Swine Health and Production 5: 21-28. 